\section{Can a cat smother and kill a baby?}

Whether a cat can smother and kill a baby was asked in the $B M F$ in 1981. ${ }^{1}$ An expert replied that it was theoretically possible but he had never heard of such a case and considered it to be an old wives' tale. ${ }^{1}$ We describe such a tragedy.

\section{Case report}

A 5-week-old previously healthy baby girl was found in her pram with a cat lying over her face. She was deeply cyanosed and gasping. Her father, a doctor, gave mouth-to-mouth resuscitation, and her colour and breathing became normal after about 30 seconds. A few hours later she had severe diarrhoea, fever, and poor peripheral circulation and was admitted to hospital. Examination showed no abnormalities apart from her blue-grey colour and tachypnoea. There was biochemical evidence of slight dehydration with severe metabolic acidosis ( $\mathrm{pH} 7 \cdot 18$ ), which was corrected. Lumbar puncture showed no abnormality, urine and cerebrospinal fluid were sterile, and no pathogenic bacteria were found in the stools. The diarrhoea stopped after two days. An electroencephalogram taken a few days later was abnormal, with spikes and waves over the frontal and temporal regions. During the next few days she had several convulsions, which responded to phenobarbitone.

Over the subsequent months her psychomotor development was clearly retarded and she again had convulsions consistent with infantile spasms. Electroencephalography showed hypsarrhythmia. She was treated with adrenocorticotrophic hormone but died at the age of 8 months from bronchopneumonia.

Postmortem examination showed bronchopneumonia as the immediate cause of death. The brain was severely shrunken and showed massive bilateral symmetrical dissolution of the white matter of the cerebral hemispheres and multiple cystic trabeculated cavities of varying size. There was severe focal atrophy of the cerebral cortex. Histologically there was massive loss of brain substance with widespread gliosis. There was loss of Purkinje cells, and some of the surviving ones had poorly demarcated fluffy borders.

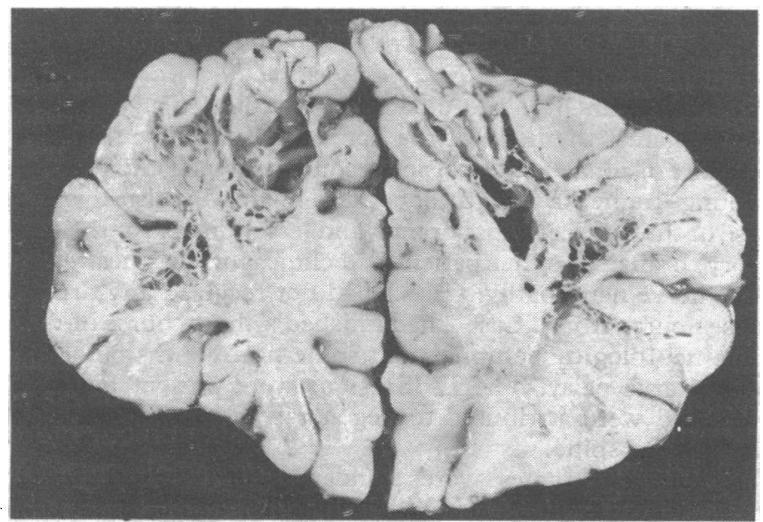

Section of brain showing bilateral symmetrical loss of white matter, forming trabeculated cystic cavities, and focal atrophy of the cortex.

\section{Comment}

This case was complicated by the fact that the baby had both asphyxia and gastroenteritis, either of which might have caused the metabolic acidosis. The brain lesions were, however, typical of those seen after severe hypoxic damage in this age group, resembling those seen after severe anoxic birth injury, ${ }^{2}$ and we suggest that they can be explained only by the smothering episode.

We found only one report of a baby smothered by a cat in the standard textbooks of paediatrics and forensic medicine. ${ }^{3}$ Some authors of popular books on child care seem to be fully aware of the risk, however, and recommend the use of a cat net to prevent a cat climbing into the cot or pram. ${ }^{45}$

It is perhaps surprising that deaths due to smothering of a baby by a cat do not occur more often, but possibly they may go undetected. It is interesting to speculate what might have happened in this case if the cat had been disturbed by the baby's movements and had jumped out of the pram before being discovered: if the baby had died it would have undoubtedly been called a cot death or sudden infant death syndrome; if she had survived and then gone on to develop a progressive nervous disease with severe psychomotor retardation and convulsions it would probably have been labelled as "infantile encephalopathy of obscure origin." In some instances children labelled with these diagnoses may, in fact, have been smothered by a cat.

1 Anonymous. Is it true that a cat can smother and kill a baby in its cot, or is this an old wives' tale? $\mathrm{Br} M e d \mathcal{F}^{1981}$;282:1679.

2 Blackwood W, Corsellis JAN, eds. Greenfield's neuropathology. London: Edward Arnold, 1976.

${ }^{3}$ Polson CJ. The essentials of forensic medicine. 2nd ed. Oxford: Pergamon Press, 1965.

4 Leach P. Baby and child. Harmondsworth: Penguin Books, 1979.

5 Jolly H. Book of child care. London: George Allen and Unwin, 1975.

(Accepted 4 Fune 1982)

Departments of Pathology and Paediatrics, University Hospital, Troms $\phi$, Norway

MICHAEL S KEARNEY, MB, MRCPATH, consultant pathologist

LAURITZ B DAHL, MD, consultant paediatrician

HELGE STALSBERG, MD, professor of pathology

\section{Glaucoma and driving}

The presence of an adequate field of vision is a necessary requirement for the driver of a motor vehicle. ${ }^{1}$ Chronic open-angle glaucoma leads to erosion of the visual field. In carrying out a survey in the Southampton area on patients with this form of glaucoma, we asked patients if they were drivers and, if so, whether they had any visual problems while driving.

\section{Patients, methods, and results}

A total of 214 patients were interviewed. In six cases the patients' glaucoma was diagnosed as a result of their becoming aware of a field defect while driving. Two patients discovered an extensive field loss in one eye when they rubbed the opposite eye. Details of the other four patients are as follows:

Case 1-A 74-year-old man, who prided himself on his driving, bumped into the kerb while driving. He then discovered that he had a visual field loss. He sought advice and on two occasions his peripheral fields were checked by confrontation. These proved to be full and he was reassured that he did not have glaucoma. As he realised that the defect was approaching fixation, he sought further advice which led to the diagnosis of glaucoma.

Case 2-A 62-year-old man found that part of the traffic lights disappeared.

Case 3-A 65-year-old man said that a car coming out of a side turning suddenly disappeared from view and then reappeared. This nearly led to a crash.

Case 4-A 58-year-old man had so many near misses that his wife refused to travel with him until he had his eyes tested. On examination he had an extensive field loss in one eye and a moderate loss in the other.

None of the six patients above had any ocular pathology apart from glaucoma. Twenty patients had given up driving because of their eye condition; of these, 13 had a further eye disease (mostly cataract) and three had given up driving after accidents. In one accident a person was killed. The driver, in this instance, was a 59-year-old man who had no other eye disease apart from glaucoma. He had an arcuate scotoma which had broken out to the periphery in the right eye and a field of less than $10^{\circ}$ in the left eye. His central vision was $6 / 6$ (right eye) and $6 / 9$ (left eye).

Out of the total of 214 patients, $61(28.5 \%)$ were still driving. All had the legally required standard of central vision. Twenty of the drivers were aged 70 years or older. Five drivers said that they were aware of their field loss and that they had made allowances for it by turning their heads (one of these was a lorry driver). One 58-year-old woman had had two near accidents and has had to leave her car in the road because she does not trust herself to miss the gate post. She has extensive field loss in both eyes as well as cataracts. Another patient, a 72-year-old man, knew that he 